\title{
Denaturing gradient gel electrophoresis of neonatal intestinal microbiota in relation to the development of asthma
}

\author{
Carl Vael $^{1^{*}}$, Liesbeth Vanheirstraeten ${ }^{1}$, Kristine N Desager $^{2}$ and Herman Goossens ${ }^{1}$
}

\begin{abstract}
Background: The extended 'hygiene hypothesis' suggests that the initial composition of the infant gut microbiota is a key determinant in the development of atopic disease. Several studies have demonstrated that the microbiota of allergic and non-allergic infants are different even before the development of symptoms, with a critical time window during the first 6 months of life. The aim of the study was to investigate the association between early intestinal colonisation and the development of asthma in the first 3 years of life using DGGE (denaturing gradient gel electrophoresis).

Methods: In a prospective birth cohort, 110 children were classified according to the API (Asthma Predictive Index). A positive index included wheezing during the first three years of life combined with eczema in the child in the first years of life or with a parental history of asthma. A fecal sample was taken at the age of 3 weeks and analysed with DGGE using universal and genus specific primers.

Results: The Asthma Predictive Index was positive in 24/110 (22\%) of the children. Using universal V3 primers a band corresponding to a Clostridum coccoides XIVa species was significantly associated with a positive API. A Bacteroides fragilis subgroup band was also significantly associated with a positive API. A final DGGE model, including both bands, allowed correct classification of $73 \%$ (80/110) of the cases.

Conclusion: Fecal colonisation at age 3 weeks with either a Bacteroides fragilis subgroup or a Clostridium coccoides subcluster XIVa species is an early indicator of possible asthma later in life. These findings need to be confirmed in a new longitudinal follow-up study.
\end{abstract}

Keywords: DGGE infant, intestinal microbiota, asthma

\section{Background}

The increasing prevalence of asthma and other atopic diseases during the last decades was originally explained by the reduced exposure to infections early in life [1]. More recently Rautava et al. [2] suggested an extension of this "hygiene hypothesis" describing the importance of the initial composition of the infant gut microbiota as a key determinant in the development of atopic disease. This hypothesis is supported by studies demonstrating that the microbiota of allergic and non-allergic infants are different even before the development of symptoms, with a critical time window during the first 6 months of

\footnotetext{
* Correspondence: carl.vael@telenet.be

'Department of Microbiology, University of Antwerp, Antwerp, Belgium Full list of author information is available at the end of the article
}

life [3]. The findings from these studies however are inconsistent: 4 different bacterial genera (Staphylococcus, Bacteroides, Clostridium, Enterobacteriaceae) are associated with an increased risk for atopic disease and 2 genera (Bifidobacterium, Lactobacillus) show a protective effect [4]. Most studies conducted so far were crosssectional focusing on atopic dermatitis, only few studies considered asthma as outcome.

Until a decade ago, most of our knowledge on the composition of the intestinal microbiota was mainly based on culture dependent techniques. Comparisons with molecular methods have indicated that culture dependent methods underestimate intestinal microbiota diversity as only $10-50 \%$ of this population is culturable [5]. About 400 different species inhabit the human 
intestine based on culture methods, but using $16 \mathrm{~S}$ rRNA sequencing more than 7000 different phylotypes were detected in the human gut [6]. Denaturing gradient gel electrophoresis (DGGE) is a molecular sequence dependent fingerprinting technique that allows to characterize the intestinal microbiota without pre-existing knowledge of its composition. DGGE using universal [7] and bifidobacterial primers [8] based on the bacterial $16 \mathrm{~S}$ rRNA sequence has been applied successfully to monitor the development of the gut microbiota in infants.

In the Asthma and Allergy study we performed DGGE analysis of bacterial $16 \mathrm{~S}$ rDNA genotypes on fecal samples to assess whether the intestinal microbiota of infants at the age of 3 weeks is associated with the development of asthma during the first 3 years of life.

\section{Methods}

The Asthma and Allergy study is a prospective birth cohort and part of the Environmental Health action of the Flemish Ministry of Health and Environment. Children $(n=158)$ were recruited through maternity clinics in Flanders. Selection criteria for enrolment in the study were vaginal delivery at term and uncomplicated perinatal period. Questionnaires were collected with data on the parents, including demography, smoking and asthma. Data of the child on demography, respiratory symptoms and risk factors for asthma were collected by postal questionnaires sent every 6 months starting at the age of 3 weeks until the age of 36 months. The question on the presence of wheezing referred to the period between two questionnaires, e.g. the presence of wheezing in the questionnaire at 6 months referred to the time period between 3 weeks and 6 months. The study protocol was approved by the medical ethics committees of the participating institutes. All parents gave written informed consent.

Symptoms of wheeze were assessed by International Study of Asthma and Allergies in Childhood core questions [9]. Information about doctor's diagnosed parental asthma was collected by the following question: 'Did a doctor ever diagnose asthma?". Based on the longitudinal questionnaire data on wheeze symptoms in the first 3 years of life, children were classified according to the 'loose' Asthma Predictive Index (API) into an API positive and an API negative group. According to the 'loose' index a positive API included wheezing during the first three years of life and eczema or parental history of asthma [10].

Approximately $2 \mathrm{~g}$ of stools was collected into a sterile recipient by the parents at 3 weeks of age. The sample was sent to the laboratory under anaerobic conditions where it was stored immediately at $-70^{\circ} \mathrm{C}$ until analysis.

DNA was extracted from fecal samples based on the method of Pitcher et al. [11] modified by Vanhoutte et al. [5]. A saline suspension of feces was made by diluting $1 \mathrm{~g}$ of wet feces in $10 \mathrm{ml}$ of sterile saline solution and homogenized using a stomacher. Of this fecal sample suspension, $1 \mathrm{ml}$ was centrifuged at 20,000 $\mathrm{g}$ for $5 \mathrm{~min}$. After removal of the supernatant, the pellet was resuspended in $1 \mathrm{ml}$ TE buffer $(10 \mathrm{mM}$ Tris- $\mathrm{HCl}, 1 \mathrm{mM}$ EDTA, pH 8.0) and was again centrifuged at 20,000 $\mathrm{g}$ for $5 \mathrm{~min}$. The pellet was resuspended in $150 \mu \mathrm{l}$ enzyme solution (6 mg lysozyme powder [Serva] and $40 \mu \mathrm{l}$ mutanolysine [Sigma] dissolved in $110 \mu \mathrm{l}$ TE $(1 \times)$ per sample) followed by incubation at $37^{\circ} \mathrm{C}$ for $40 \mathrm{~min}$. Next, $500 \mu \mathrm{l}$ GES reagent (GuanidiumthiocyanateEDTA-Sarkosyl; $600 \mathrm{~g} \mathrm{l}^{-1}$ guanidiumthiocyanate [Sigma], $200 \mathrm{ml} \mathrm{l}^{-1}$ 0.5 M EDTA, $10 \mathrm{~g} \mathrm{l}^{-1}$ sarkosyl) was added to complete all lysis, after which the solution was put on ice for $10 \mathrm{~min}$. In the following step, $250 \mu \mathrm{l}$ ammonium acetate $(7.5 \mathrm{M})$ was added and the mixture was put on ice for $10 \mathrm{~min}$. Subsequently, two chloroform-isoamylalcohol extractions were performed with $500 \mu \mathrm{l}$ chloroform/iso-amylalcohol solution (24/1). Finally, DNA was precipitated by adding 0.54 volumes of icecold isopropanol. After centrifugation at 20,000 $\mathrm{g}$ for $5 \mathrm{~min}$, the pellet was washed twice with $150 \mu \mathrm{l} 70 \%$ $\mathrm{EtOH}$, air dried and allowed to dissolve overnight in $150 \mu \mathrm{l}$ TE $(1 \times)$ buffer. The remaining RNA was removed by adding $7.5 \mu \mathrm{l}$ RNase $\left(2 \mathrm{mg} \mathrm{ml}^{-1}\right.$; Serva) after which samples were incubated for $1.5 \mathrm{~h}$ at $37^{\circ} \mathrm{C}$. Purified DNA extracts were stored at $-20^{\circ} \mathrm{C}$.

PCR was performed with a Taq polymerase kit (Supertaq, HT Biotechnology Ltd). Each PCR mixture $(50 \mu \mathrm{l})$ contained $6 \mu \mathrm{l} 10 \times$ PCR buffer (containing $15 \mathrm{mM}$ $\mathrm{MgCl}_{2}$ ), $2.5 \mu$ l Bovine Serum Albumin $\left(0.1 \mathrm{mg} \mathrm{ml}^{-1}\right)$, $2.5 \mu \mathrm{d}$ dNTP preparation (containing each dNTP at a concentration of $2 \mathrm{mM}), 2 \mu \mathrm{l}$ of each primer $(5 \mu \mathrm{M})$; $0.25 \mu \mathrm{Taq}$ polymerase, $33.75 \mu \mathrm{l}$ sterile Milli-Q water and $1 \mu \mathrm{l}$ of 10 -fold diluted DNA solution. One single PCR core program was used for all primer pairs: initial denaturation at $94^{\circ} \mathrm{C}$ for $5 \mathrm{~min}$; 30 cycles of denaturation at $94^{\circ} \mathrm{C}$ for $20 \mathrm{~s}$, annealing at primer-specific temperature (Table 1) for $45 \mathrm{~s}$ and extension at $72^{\circ} \mathrm{C}$ for $1 \mathrm{~min}$; and final extension at $72^{\circ} \mathrm{C}$ for $7 \mathrm{~min}$ followed by cooling to $4^{\circ} \mathrm{C}$. PCR amplicons were verified with electrophoresis in a $1.5 \%$ agarose gel after staining with ethidium bromide $(50 \mu \mathrm{l}$ in $500 \mathrm{ml} 1 \times$ TAE buffer [TE buffer with $5.71 \%$ (vol/vol) acetic acid]) with a 100-bp molecular ruler (Invitrogen) to compare with the expected amplicon size for the corresponding primer set (table 1) (data not shown). PCR amplification products were stored at $-20^{\circ} \mathrm{C}$.

$16 \mathrm{~S}$ rRNA gene amplicons were analyzed with DGGE as described previously [12]. In our study, different types of denaturing gradient were applied depending on the primers used (table 1 ). The polyacrylamide gels ( 160 by 160 by $1 \mathrm{~mm}$ ) consisted of $8 \%$ (vol/vol) polyacrylamide (Biorad) in $1 \times$ TAE buffer. By diluting a $100 \%$ denaturing polyacrylamide solution (containing $7 \mathrm{M}$ urea 
Table 1 Specifications of the 16S rRNA primers used in this study

\begin{tabular}{|c|c|c|c|c|c|c|}
\hline $\begin{array}{l}\text { Target group (variable } \\
\text { region) }\end{array}$ & $\begin{array}{l}\text { Primer } \\
\text { designation }\end{array}$ & Primer sequence $\left(5^{\prime}-3^{\prime}\right)$ & $\begin{array}{l}\text { Amplicon } \\
\text { size }\end{array}$ & $\begin{array}{l}\text { Annealing } \\
\text { temperature }\end{array}$ & $\begin{array}{l}\text { DGGE } \\
\text { gradient }\end{array}$ & Reference \\
\hline Universal (V3) & $\begin{array}{l}\text { F357-GC }^{a} \\
518 R\end{array}$ & $\begin{array}{l}\text { TACGGGAGGCAGCAG } \\
\text { ATTACCGCGGCTGCTGG }\end{array}$ & 217 & $55^{\circ} \mathrm{C}$ & $20-70 \%$ & $\begin{array}{l}\text { Muyzer et al., } \\
1993\end{array}$ \\
\hline Universal (V6-V8) & $\begin{array}{l}\text { U968F-GC } \\
\text { L1401-R }\end{array}$ & $\begin{array}{l}\text { AACGCGAAGAACCTTAC } \\
\text { CGGTGTGTACAAGACCC }\end{array}$ & 489 & $55^{\circ} \mathrm{C}$ & $20-70 \%$ & $\begin{array}{l}\text { Zoetendal et al., } \\
1998\end{array}$ \\
\hline $\begin{array}{l}\text { Bacteroides fragilis } \\
\text { subgroup }\end{array}$ & $\begin{array}{l}\text { Bfra 531F } \\
\text { Bfra 766R-GC }\end{array}$ & $\begin{array}{l}\text { ATACGGAGGATCCGAGCGTTA } \\
\text { CTGTTTGATACCCACACT }\end{array}$ & 293 & $65^{\circ} \mathrm{C}$ & $20-70 \%$ & $\begin{array}{l}\text { Vanhoutte et al., } \\
2006\end{array}$ \\
\hline Bifidobacterium & $\begin{array}{l}\text { g-Bifid F } \\
\text { g-Bifid R-GC }\end{array}$ & $\begin{array}{l}\text { CTCCTGGAAACGGGTGG } \\
\text { GGTGTTCTTCCCGATATCTACA }\end{array}$ & 596 & $65^{\circ} \mathrm{C}$ & $40-70 \%$ & $\begin{array}{l}\text { Matsukiu et al., } \\
2002\end{array}$ \\
\hline Lactobacillus group $^{b}$ & $\begin{array}{l}\operatorname{Lac} 1 \\
\operatorname{Lac}^{-G}-\mathrm{GC}^{a}\end{array}$ & $\begin{array}{l}\text { AGCAGTAGGGAATCTTCCA } \\
\text { ATTYCACCGCTACACATG }\end{array}$ & 380 & $61^{\circ} \mathrm{C}$ & $35-60 \%$ & Walter et al., 2001 \\
\hline
\end{tabular}

a Primers with GC clamp at $5^{\prime}$ end: CGCCCGCCGCGCCCCGCGCCCGGCCCGCCGCCCCCGCCCC.

${ }^{\mathrm{b}}$ Lactobacillus group comprising the genera Lactobacillus, Leuconostoc, Pediococcus and Weisella.

[Biorad] and 40\% formamide [Sigma]) with a polyacrylamide solution containing no denaturing components, polyacrylamide solutions with the desired denaturing percentages were obtained. The 24-ml gradient gels were cast by using a gradient former (Biorad) and a pump (Biorad) set at a constant speed of $5 \mathrm{ml} / \mathrm{min}$. The denaturing gels were allowed to polymerize for $3 \mathrm{~h}$, after which a $5-\mathrm{ml}$ nondenaturing stacking gel containing a 16 -well comb was poured on top. After $1 \mathrm{~h}$ of polymerization, PCR samples were loaded into the wells, and electrophoresis was performed for $16 \mathrm{~h}$ at $70 \mathrm{~V}$ in $1 \times \mathrm{TAE}$ buffer at a constant temperature of $60^{\circ} \mathrm{C}$ by using the Dcode system (Biorad). DGGE gels were stained for 30 min with $1 \times \mathrm{SYBR}^{\circledR}$ Gold (Molecular Probes) in $1 \times$ TAE buffer. This was followed by visualization of DGGE band profiles under UV light. Digital capturing was performed by using a Geldoc XR camera system (Biorad) combined with the Quantity One software package (Biorad). By including a standard reference every six lanes in each DGGE gel, it was possible to digitally normalize the gel profiles by comparison with a standard pattern using the BioNumerics software, version 2.5 (Applied Maths, St.-Martens-Latem, Belgium). This normalization enabled comparison between DGGE profiles from different gels provided that these were run under comparable denaturing and electrophoresis conditions.

The digitalized data were exported as an excel file for further statistical analysis according to Gafan et al. [13]. In this file, each sample represented 1 row and each band was assigned to a unique band position (column) with 1 indicating presence and 0 indicating absence of a band at that position. API was used as outcome parameter. The data were first analysed using Chi-square tests with a cut-off for significance at $5 \%$ to reduce the number of bands included in multivariate analysis. Significant bands (absent coded as 0 , present coded as 1 ) were included as explanatory variables in a multivariate logistic regression analysis (API as dependent variable, negative coded as 0 , positive as 1 ) for each primer set separately. The estimated odds ratio was calculated for each band in the logistic regression model. Bands remaining significantly associated with the API index in this model were adjusted for 5 known asthma confounders (exclusive breast feeding, maternal smoking during pregnancy, infant use of antibiotics at age of 3 weeks, parental socio-economic status and gender) in a second logistic regression model. The statistical analysis was conducted using SPSS version 15 (Chicago, USA).

Significant bands in this second model were identified after excision of the band from the gel and overnight incubation in TE buffer at $4^{\circ} \mathrm{C}$. After extraction of the band it was reamplified with the corresponding primer set and reanalysed in DGGE together with the original fecal sample to confirm if the correct band was extracted. This process was repeated 2-3 times until a single band was obtained. This band was subsequently sequenced without additional cloning by the Genetic Service Facility (VIB, University of Antwerp) with a capillary sequencer (Applied Biosystems 3730 DNA analyser) using the corresponding forward and reverse primers without the GC clamp. In all cases this procedure resulted in a pure sequence product from the excised band. The obtained sequences were analysed using the BLAST program.

\section{Results}

\section{Description of the study population}

Of the 158 children recruited in this study, 54\% were boys. Maternal or paternal asthma was present in $8 \%$ and $5 \%$ of the children, respectively. Several children were lost for follow-up at the end of the 3 year study period. As a result, API at age 3 years could not be determined in 41 of the 158 children due to missing data on wheezing $(n=30)$ or on eczema $(n=9)$ of the child in the 6 monthly questionnaires or on parental asthma $(n=5)$. As described previously, there were no differences in the percentage of children with wheeze at any age, parental asthma, and eczema at any age or 
gender of the infant between children who could or could not be categorized according to API [14]. In 7 children insufficient fecal sample was available to perform a DGGE analysis. API was positive in 24/110 $(22 \%)$ of the remaining children.

\section{Fecal microorganisms in the study population}

A total of 145 fecal samples were collected, which is a response rate of $92 \%$.

The Lactobacillus and Bifidobacterium primers did not show any correlation with the API index (data not shown). With the universal V6-V8 primers only 1 single band (band 54.2) correlated significantly with the API index (Chi square, $\mathrm{p}=0.04$ ). After adjustment for exclusive breast feeding, maternal smoking during pregnancy, infant use of antibiotics at age of 3 weeks, parental socio-economic status and gender in a multivariate logistic regression analysis, the V6-V8 band 54.2 remained significantly associated with the API index $(\mathrm{OR}=4.0$, CI 1.2-12.9) (table 2). Excision and sequencing of band 54.2 revealed a DNA fragment of $397 \mathrm{bp}$ [EMBL:FN611010] showing 98\% similarity with an uncultured bacterial sequence isolated from a human fecal sample (table 3 ). The highest sequence similarity with a known species was obtained for Eubacterium contortum, Clostridium oroticum and Ruminococcus torques (table 3). These species belong to the Clostridium subcluster XIVa proposed by Collins et al. [15], which constitutes a major part of the human fecal flora [16].

With the universal V3 primers only 2 bands (band 60.1 and 95.0) correlated significantly with the API index (Chi square, respectively $\mathrm{p}=0.03$ and $\mathrm{p}=0.04$ ). In a logistic regression analysis including both bands, only band 60.1 (OR = 5,9; CI 1,1 - 7,9) remained independently associated with the API index (band 95.0: OR $=5.710^{9}$; CI 0 - NA). After further adjustment for confounders in a multivariate logistic regression analysis, the V3 band 60.1 remained significantly associated with the API index (table 2). Excision and sequencing of band 60.1 revealed a DNA fragment of 139 bp [EMBL: FN611009] showing 100\% similarity with an uncultured bacterial sequence isolated from a human fecal sample (table 3). The highest sequence similarity with a known species was obtained for Ruminococcus productus or hansenii and Clostridium sp (table 3). These species also belong to the Clostridium subcluster XIVa proposed by Collins et al. [15] with Clostridium coccoides as their nearest neighbour.

With the Bacteroides fragilis subgroup primers 4 bands (band 18.4; 27.3; 45.9 and 57.9) correlated significantly with the API index (Chi square, respectively $\mathrm{p}=$ $0.008 ; 0.048 ; 0.006$ and 0.048 ). In a logistic regression analysis including all 4 bands only band $45.9(\mathrm{OR}=7.1$; CI $1,1-46,1)$ remained independently associated with the API index (band 18.4: OR = 4,8; CI 0,3 - 80,0/band 27.3: $\mathrm{OR}=8,610^{7}$; CI 0 - NA/band 57.9: OR = 8,6 107 CI 0 - NA). After adjustment for confounders, the Bacteroides fragilis subgroup band 45.9 remained significantly associated with the API index (table 2). Excision and sequencing of band 45.9 revealed a DNA fragment of 241 bp [EMBL:FN611011] showing 99\% similarity with Bacteroides fragilis (table 3). A similarity of 98 and 97\% was found with respectively Bacteroides finegoldii and Bacteroides thetaiotaomicron (table 3). In a final logistic regression model including the 3 significant DGGE bands only V3 band $60.1(\mathrm{OR}=3,4$; CI $1,2-9,7)$ and the Bacteroides fragilis subgroup band 45.9 (OR = 9,8; CI 1,6 - 59,3) proved to be independent variables excluding the V6-V8 band $54.2(\mathrm{OR}=2,3$; CI $0,7-7,8)$ from the model. After adjustment for confounders, this simple final DGGE model including only 2 bands (band 60.1 and band 45.9) remained significantly associated

Table 2 Multiple logistic regression analysis of risk factors for outcome variable Asthma Predictive Index at age 3 years

\begin{tabular}{|c|c|c|c|c|c|c|c|c|}
\hline \multirow[b]{2}{*}{ Variable } & \multicolumn{2}{|c|}{ V6-V8 band 54.2} & \multicolumn{2}{|c|}{ V3 band 60.1} & \multicolumn{2}{|c|}{ BF band 45.9} & \multicolumn{2}{|c|}{ Final DGGE model* } \\
\hline & OR & $\mathbf{P}$ & OR & $\mathbf{P}$ & OR & $\mathbf{P}$ & OR & $P$ \\
\hline Presence of a DGGE band at the age of 3 weeks (yes versus no) & 4,0 & 0,02 & 3,6 & 0,02 & 10,5 & 0,008 & 4,7 & 0,002 \\
\hline $\begin{array}{l}\text { Exclusive breastfeeding age below the age of } 3 \text { weeks } \\
\text { (yes versus no) }\end{array}$ & 1,4 & 0,58 & 1,5 & 0,47 & 1,1 & 0,90 & 1,5 & 0,50 \\
\hline Maternal smoking during pregnancy (yes versus no) & 1,4 & 0,69 & 1,7 & 0,56 & 1,6 & 0,58 & 1,9 & 0,47 \\
\hline $\begin{array}{l}\text { Infant use of antibiotics below the age of } 3 \text { weeks } \\
\text { (yes versus no) }\end{array}$ & 0 & 1,0 & 0 & 1,0 & 0 & 1,0 & 0 & 1,0 \\
\hline Parental socioeconomic status (low versus high) & 1,1 & 0,86 & 1,1 & 0,92 & 1,3 & 0,64 & 1,1 & 0,86 \\
\hline Infant gender (male versus female) & 0,5 & 0,22 & 0,6 & 0,26 & 0,7 & 0,51 & 0,6 & 0,29 \\
\hline
\end{tabular}

Odds ratios are adjusted for the independent variables, indicated in the rows of the table.

OR: adjusted odds ratio.

$P$ : $P$ value.

BF: Bacteroides fragilis subgroup.

* Final DGGE model: a combination of V3 band 60.1 (Clostridium coccoides subcluster XIVa) and Bacteroides fragilis subgroup band 45.9 . 
Table 3 BLAST identifications of the excised DGGE bands

\begin{tabular}{|c|c|c|c|c|c|c|c|}
\hline \multicolumn{3}{|c|}{ DGGE amplicon } & \multicolumn{2}{|c|}{ Identification } & \multirow{2}{*}{$\begin{array}{l}\text { Sequence } \\
\% \text { identity }\end{array}$} & \multicolumn{2}{|c|}{ \# Bp } \\
\hline Band $\mathrm{nr}$ & Primer & \# Bp & Species & Accession $\mathrm{Nr}$ & & Identical & Total \\
\hline \multirow[t]{4}{*}{54.2} & $\begin{array}{l}\text { L1401-R } \\
\text { (V6-V8) }\end{array}$ & 397 & Uncultured bacterium & EF405354.1 & 98 & 385 & 389 \\
\hline & & & Eubacterium contortum & L34615.1 & 93 & 364 & 390 \\
\hline & & & Clostridium oroticum & M59109.1 & 94 & 367 & 389 \\
\hline & & & Ruminococcus torques & L76604.1 & 93 & 365 & 389 \\
\hline \multirow[t]{4}{*}{60.1} & $\begin{array}{l}518 R \\
\text { (V3) }\end{array}$ & 139 & Uncultured bacterium & EF403112.1 & 100 & 124 & 124 \\
\hline & & & Ruminococcus productus & AY937379.1 & 98 & 122 & 124 \\
\hline & & & Clostridium sp. & Y10584.1 & 98 & 122 & 124 \\
\hline & & & Ruminococcus hansenii & M59114.1 & 97 & 121 & 124 \\
\hline \multirow[t]{3}{*}{45.9} & Bfra 531F & 241 & Bacteroides fragilis & DQ100447.1 & 99 & 210 & 211 \\
\hline & & & Bacteroides finegoldii & AB222700.1 & 98 & 207 & 211 \\
\hline & & & Bacteroides thetaiotaomicron & AY319392.1 & 97 & 206 & 211 \\
\hline
\end{tabular}

with the API index (table 2). The accuracy of predicting asthma at the age of 3 years using this final DGGE model is shown in table 4 . The model allows correct classification of $73 \%(80 / 110)$ of the cases.

This means that, according to our findings, early intestinal colonization of infants with bacteria belonging to the Bacteroides fragilis group and/or to the Clostridium coccoides subcluster XIVa is associated with an increased risk for the development of asthma at the age of 3 years. These bacteria are strict anaerobes and are part of the dominant genera of the normal intestinal microbiota observed in adults. We could not detect any bacterial taxa that were associated with health (API negative status). Lactobacillus and Bifidobacterium, the bacterial genera generally used as probiotics and considered by definition of having a beneficial effect on health

Table 4 Accuracy of final DGGE model* in predicting API status at age 3 years

\begin{tabular}{lllll}
\hline \multicolumn{4}{c}{ API index } & N \\
& Pos & Neg & & \\
\hline DGGE model Pos. & 13 & 19 & 32 & PPV $=41 \%$ \\
DGGE model Neg. & 11 & 67 & 78 & NPV $=86 \%$ \\
Total & 24 & 86 & 110 & \\
\hline & $54 \%$ S & $78 \%$ Sp & & $X^{2}, p=0.002$ \\
\hline
\end{tabular}

Overall correct classification: $80 / 110=73 \%$.

API prevalence: $24 / 110=22 \%$.

Final DGGE model:

Positive: presence of band 60.1 (Clostridium coccoides subcluster XIVa) or band 45.9 (Bacteroides fragilis subgroup).

Negative: absence of band 60.1 (Clostridium coccoides subcluster XIVa) and band 45.9 (Bacteroides fragilis subgroup).

$\mathrm{N}$ : number of cases.

PPV: positive predictive value.

NPV: negative predictive value.

S: sensitivity.

Sp: specificity. could not be associated with a reduced risk of asthma. However it cannot be excluded that our inability to demonstrate a beneficial effect of certain bacterial taxa on infant health was caused by the limited sensitivity of the DGGE method that we used.

\section{Discussion}

This study shows an association between early colonisation with a Bacteroides fragilis subgroup species and asthma later in life. We also showed in this study that a Clostridium coccoides subcluster XIVa species is an early indicator of asthma later in life. This is the first prospective study that links Clostridium coccoides subcluster XIVa to API, a clinically relevant risk factor for developing asthma. Differences in feeding pattern, use of antibiotics, gender, maternal smoking in pregnancy or parental socio-economic status cannot explain the findings.

Asthma is a frequently occurring condition in children with up to $50 \%$ of infants and children suffering of one or more episodes of wheezing below the age of 6 years. The diagnosis of asthma is not straightforward since no simple clinical tools are available to discriminate children prone to develop persistent asthma from those who will not. The 'Asthma Prediction Index' has been associated with an increased risk for asthma at school age [10]. This index was chosen as outcome parameter for the study since it is at present the best tool for prediction of asthma at school age. We used the so-called 'loose' index, which only required infrequent wheezing episodes in early life combined with risk factors for asthma because it has a much higher sensitivity (39\%) but slightly lower specificity (82\%) and positive predictive value $(32 \%)$ than the so-called "stringent" index. The negative predictive value at all ages was very high for both indices, suggesting that the great majority of 
children who did not develop asthma during the school years had a negative predicted index during the first years of life. Because the Asthma Predictive Index is only an approximation to predict which children will subsequently develop persistent asthma, further followup at school age is required to definitely determine the relation between early Bacteroides fragilis and Clostridium coccoides subcluster XIVa colonisation and asthma.

With the exception of our previous study [14] using conventional culture methods, there are no data linking the Bacteroides fragilis subgroup to asthma but several studies showed a correlation between Bacteroides and allergy: A higher IgG immune response to Bacteroides vulgaris was found in high school children with allergic symptoms [17]. A positive correlation between the fecal counts of Bacteroides and the serum IgE concentration was demonstrated in 2 studies, one in infants intolerant to an extensively hydrolysed formula [18] and one in non-allergic children at the age of 5 years [19]. A study in adults with pollen allergy showed an increased ratio of fecal counts of Bacteroides fragilis to Bifidobacterium during pollen season. In vitro, using peripheral blood mononuclear cells of these patients, they also demonstrated that Bacteroides fragilis strains induced more Th2 cytokines but fewer Th1 cytokines compared with Bifidobacterium strains [20]. We believe that intestinal Bacteroides species might be able to induce a Th2 cytokine response through binding of a TLR2 (Toll-like receptor) present on intestinal dendritic cells. Netea et al. showed that Bacteroides species stimulate cytokine release through TLR2-dependent (not TLR4) mechanisms [21]. TLR2 agonists induce a Th2 response by suppressing IL-12 production [22].

Fecal Clostridium colonisation in infants has been linked to asthma before: A higher level of $C$. difficilespecific IgG was found in one-year-old children with recurrent wheezing [23]. A higher prevalence of C. difficile was detected using quantitative real-time PCR in infants who developed recurrent wheeze during the first 2 years of life [24]. C. difficile belongs to Clostridium cluster XI and is only remotely related to the Clostridium coccoides subcluster XIVa species that we detected [15]. These differences might be explained by the use of different methods (DGGE versus quantitative PCR or serology) and because different clinical outcomes were determined (API at the age of 3 years versus recurrent wheezing at the age of 1 or 2 years). In adult fecal microbiota Clostridium coccoides subcluster XIVa is the most abundant taxonomic group [16] but in infants it normally constitutes only a subdominant group at much lower counts [25]. Through the peptidoglycan present in their bacterial cell membrane the intestinal Clostridium species might be able to induce a
Th2 cytokine response by binding to the TLR2 of the intestinal dendritic cells [21,22].

Several studies used DGGE to examine the relationship between the composition of the intestinal microbiota and the development of allergy and eczema [26-28]. In a case-control study, the prevalence of one specific DGGE band (identified as E. coli) was higher in infants with eczema [26]. A reduced fecal microbial diversity was observed with DGGE in allergic children [27] or in infants with eczema [28]. Only one study looked at wheezing as outcome using DGGE but did not find a difference in gut microbiota between wheezing and non-wheezing children at the age of 3-5 years [29]. We found a difference in the composition of the fecal microbiota at the age of 3 weeks but not later (at the age of 6 and 12 months; data not shown), illustrating the importance of a critical time window during the first 6 months of life [3].

Prematurity is a much more complex situation than the normal population observed in our study. A delay of up to 6 months of the intestinal Bacteroides colonization, which occurs in newborns after caesarean section, might even decrease the subsequent risk for asthma in these premature infants according to our findings. However, genetic factors or the underlying disease that provoked the premature delivery itself might significantly increase the subsequent risk for asthma. Future studies on premature newborns and their respiratory disease outcome should not only include the intestinal microbiota but should also correct for confounders like antibiotic use, mode of delivery and underlying disease or genetic mutations.

Despite obvious advantages, DGGE also has a limitation. The detection limit of DGGE is estimated to approach $1 \%$ of the total population or a concentration of $10^{6} \mathrm{CFU} / \mathrm{g}$ feces. This is significantly higher than the detection limit of the culture method we used in our previous study (detection limit $\geq 10^{3} \mathrm{CFU} / \mathrm{g}$ feces) [14]. Another limitation of the present study is the fact that no stool sample of the mother was included, so we cannot make any statement on the origin of the Bacteroides and Clostridium strains recovered in these infants. Finally, as in every longitudinal study, missing data is a problem. Since there were no differences in the percentage of children with wheezing, eczema or parental asthma or gender of the infant between children who could or could not be categorized according to API, it seems improbable that the missing data resulted in a systemic bias. Adjustment for known confounders in a multivariate logistic regression analysis further confirmed our findings.

\section{Conclusions}

Fecal colonisation at age 3 weeks with either a Bacteroides fragilis subgroup or a Clostridium coccoides 
subcluster XIVa species is an early indicator of possible asthma later in life. These findings need to be confirmed in a new longitudinal follow-up study. The effect of preand probiotics on the intestinal colonization with Clostridium and Bacteroides requires further attention in future trials for the prevention of asthma in infants and children.

\section{Abbreviations}

API: Asthma Predictive Index; Cl: confidence interval; DGGE: denaturing gradient gel electrophoresis; TLR: Toll-like receptor

\section{Acknowledgements}

We thank A. De Coninck and C. Lammens for their technical assistance. Funded by the Flemish Government 'Health and Environment, subdivision Asthma'

\section{Author details}

${ }^{1}$ Department of Microbiology, University of Antwerp, Antwerp, Belgium ${ }^{2}$ Department of Pediatrics, University of Antwerp, Antwerp, Belgium.

\section{Authors' contributions}

CV was involved in the study design and concept, helped to draft and revise the manuscript and performed the statistical analysis. LV assisted in the data acquisition and helped revising the manuscript. HG was involved in the study design and concept and helped revising the manuscript. KD was involved in the study design and concept and helped to revise the manuscript. All authors read and approved the final manuscript.

\section{Competing interests}

The authors declare that they have no competing interests.

Received: 19 October 2010 Accepted: 10 April 2011

Published: 10 April 2011

\section{References}

1. Strachan DP: Hay fever, hygiene, and household size. BMJ 1989 299:1259-1260

2. Rautava S, Ruuskanen O, Ouwehand A, Salminen S, Isolauri E: The hygiene hypothesis of atopic disease-an extended version. J Pediatr Gastroenterol Nutr 2004, 38:378-388.

3. Penders J, Stobberingh EE, van den Brandt PA, Thijs C: The role of the intestinal microbiota in the development of atopic disorders. Allergy 2007, 62:1223-1236.

4. Vael $C$, Desager $K$ : The importance of the development of the intestinal microbiota in infancy. Curr Opin Pediatr 2009, 21:794-800.

5. Vanhoutte T, Huys G, Brandt E, Swings J: Temporal stability analysis of the microbiota in human feces by denaturing gradient gel electrophoresis using universal and group-specific 16S rRNA gene primers. FEMS Microbiol Ecol 2004, 48:437-446.

6. Gaskins HR, Croix JA, Nakamura N, Nava GM: Impact of the intestinal microbiota on the development of mucosal defense. Clin Infect Dis 2008, 46(Suppl 2):S80-S86.

7. Favier CF, Vaughan EE, de Vos WM, Akkermans AD: Molecular monitoring of succession of bacterial communities in human neonates. Appl Environ Microbiol 2002, 68:219-226.

8. Favier CF, de Vos WM, Akkermans AD: Development of bacterial and bifidobacterial communities in feces of newborn babies. Anaerobe 2003, 9:219-229.

9. Pearce N, Weiland S, Keil U, Langridge P, Anderson HR, Strachan D, et al: Self-reported prevalence of asthma symptoms in children in Australia, England, Germany and New Zealand: an international comparison using the ISAAC protocol. Eur Respir J 1993, 6:1455-1461.

10. Castro-Rodriguez JA, Holberg CJ, Wright AL, Martinez FD: A Clinical Index to Define Risk of Asthma in Young Children with Recurrent Wheezing. Am J Respir Crit Care 2000, 162:1403-1406.

11. Pitcher D, Saunders N, Owen R: Rapid extraction of bacterial genomic DNA with guanidium thiocyanate. Lett Appl Microbiol 1989, 8:151-156.
12. Temmerman R, Scheirlinck I, Huys G, Swings J: Culture-independent analysis of probiotic products by denaturing gradient gel electrophoresis. Appl Environ Microbiol 2003, 69:220-226.

13. Gafan GP, Lucas VS, Roberts GJ, Petrie A, Wilson M, Spratt DA: Statistical analyses of complex denaturing gradient gel electrophoresis profiles. $J$ Clin Microbiol 2005, 43:3971-3978.

14. Vael C, Nelen V, Verhulst SL, Goossens H, Desager KN: Early intestinal Bacteroides fragilis colonisation and development of asthma. BMC Pulm Med 2008, 8:19.

15. Collins MD, Lawson PA, Willems A, Cordoba JJ, Fernandez-Garayzabal J, Garcia $P$, et al: The phylogeny of the genus Clostridium: proposal of five new genera and eleven new species combinations. Int J Syst Bacteriol 1994, 44:812-826.

16. Suau A, Bonnet R, Sutren M, Godon JJ, Gibson GR, Collins MD, et al: Direct analysis of genes encoding $16 \mathrm{~S}$ rRNA from complex communities reveals many novel molecular species within the human gut. Appl Environ Microbiol 1999, 65:4799-4807.

17. Fukuda S, Ishikawa H, Koga $Y$, Aiba $Y$, Nakashima $K$, Cheng L, et al: Allergic symptoms and microflora in schoolchildren. J Adolesc Health 2004, 35:156-158.

18. Kirjavainen PV, Arvola T, Salminen SJ, Isolauri E: Aberrant composition of gut microbiota of allergic infants: a target of bifidobacterial therapy at weaning? Gut 2002, 51:51-55.

19. Sepp E, Julge K, Mikelsaar M, Bjorksten B: Intestinal microbiota and immunoglobulin E responses in 5-year-old Estonian children. Clin Exp Allergy 2005, 35:1141-1146.

20. Odamaki T, Xiao JZ, Iwabuchi N, Sakamoto M, Takahashi N, Kondo S, et al: Fluctuation of fecal microbiota in individuals with Japanese cedar pollinosis during the pollen season and influence of probiotic intake. $J$ Investig Allergol Clin Immunol 2007, 17:92-100.

21. Netea MG, Kullberg BJ, de Jong DJ, Franke B, Sprong T, Naber TH, et al: NOD2 mediates anti-inflammatory signals induced by TLR2 ligands: implications for Crohn's disease. Eur J Immunol 2004, 34:2052-2059.

22. Agrawal S, Agrawal A, Doughty B, Gerwitz A, Blenis J, Van Dyke T, et al: Cutting edge: different Toll-like receptor agonists instruct dendritic cells to induce distinct Th responses via differential modulation of extracellular signal-regulated kinase-mitogen-activated protein kinase and c-Fos. J Immunol 2003, 171:4984-4989.

23. Woodcock A, Moradi M, Smillie Fl, Murray CS, Burnie JP, Custovic A: Clostridium difficile, atopy and wheeze during the first year of life. Pediatr Allergy Immunol 2002, 13:357-360.

24. Penders J, Thijs C, van den Brandt PA, Kummeling I, Snijders B, Stelma F, et al: Gut microbiota composition and development of atopic manifestations in infancy: the KOALA Birth Cohort Study. Gut 2007, 56:661-667.

25. Mariat D, Firmesse O, Levenez F, Guimaraes V, Sokol H, Dore J, et al: The Firmicutes/Bacteroidetes ratio of the human microbiota changes with age. BMC Microbiol 2009, 9:123

26. Penders J, Stobberingh EE, Thijs C, Adams H, Vink C, van Ree R, et al: Molecular fingerprinting of the intestinal microbiota of infants in whom atopic eczema was or was not developing. Clin Exp Allergy 2006, 36:1602-1608.

27. Stsepetova J, Sepp E, Julge K, Vaughan E, Mikelsaar M, de Vos WM: Molecularly assessed shifts of Bifidobacterium ssp. and less diverse microbial communities are characteristic of 5-year-old allergic children. FEMS Immunol Med Microbiol 2007, 51:260-269.

28. Forno E, Onderdonk AB, McCracken J, Litonjua AA, Laskey D, Delaney ML, et al: Diversity of the gut microbiota and eczema in early life. Clin $\mathrm{Mol}$ Allergy 2008, 6:11.

29. Murray CS, Tannock GW, Simon MA, Harmsen HJ, Welling GW, Custovic A, et al: Fecal microbiota in sensitized wheezy and non-sensitized nonwheezy children: a nested case-control study. Clin Exp Allergy 2005, 35:741-745.

doi:10.1186/1471-2180-11-68

Cite this article as: Vael et al:: Denaturing gradient gel electrophoresis of neonatal intestinal microbiota in relation to the development of asthma. BMC Microbiology 2011 11:68. 